\author{
Rodrigo Morales Salazar \\ Magíster en Teoría e Historia del Arte \\ Universidad de Chile \\ r.rodrigo.m@gmail.com
}

\title{
Opacidad en deuda
}

\section{The Opacity Indebted}

\section{Resumen}

Escrito articulado en tres movimientos: el primero de ellos, revisa la posibilidad de pensar el poema como acceso, deuda y exacción, basado en los escritos de Jean-Luc Nancy, especialmente en su ensayo "Hacer, la poesía". El segundo momento se vincula con pensar el poema en relación con la violencia que lo constituye. Y, por último, nos acercamos al pensamiento de Maurice Blanchot, para indagar sobre el estrecho vínculo entre poema y desastre.

Palabras clave: poema, deuda, exacción, acceso, desastre, violencia.

\begin{abstract}
Text articulated in three movements: the first, reviews the possibility of thinking the poem as access, debt and exaction, based on the writings of Jean-Luc Nancy, especially in his essay "Do, the poetry." The second moment is related to thinking the poem in connection with the violence that constitutes it. And finally, we approach the thought of Maurice Blanchot, to inquire about the close link between poem and disaster.
\end{abstract}

Keywords: poem, debt, exaction, access, disaster, violence.

I.

En su ensayo "Hacer, la poesía", Jean-Luc Nancy aborda el problema de la poesía diríamos en un principio- de dos formas siempre problemáticas. Primero, se plantea la posibilidad de que el poema venga a completar la forma de su reverso: "La poesía es también la negatividad en el sentido que niega, en el acceso al sentido, lo que determinaría el acceso como un pasaje, una vía o un camino, y que lo afirma como una presencia, una invasión" (Nancy, 2013; 122). Luego, bajo la misma comprensión, como algo exacto y definitivo, bajo lo cual solo lo que 
accede puede ser visitado por el poema: "El poema o el verso, designa la unidad de elocución de una exactitud. Esa elocución es intransitiva: no reenvía al sentido como a un contenido, no lo comunica, sino que lo hace, siendo exacta y literalmente la verdad" (Nancy, 2013; 124). Entonces, por un lado, una lectura anversa sobre la posibilidad de la negación y la dificultad, y al mismo tiempo, una particular relación con la verdad, la exactitud.

La lectura del poema parte, por un lado, con una escisión -fractura inviable e inexactahacia una memoria todavía en oscuridad, y por un resto que parte, vacía y distrae de su sombra, tal vez, allí signada como espacio otro y simultáneo, de eso que estando allí no deja de partir-se. No tiene partir - ni volver- porque hay falta, su propia condición de deuda como sentido del acceso a esas palabras llamadas a errar, y como una errancia en deuda, extravía el abandono de esa mano que vuelve a escribir la violencia (Nancy, 2002; 45).

Advirtiendo sobre la oscuridad de su carácter, Nancy plantea que "negándose, la poesía niega que el acceso al sentido pueda ser confundido con un modo cualquiera de expresión o de figuración" (Nancy, 2013; 120-121). Comprometida en ella por su negación, la poesía niega, dice no. Negatividad que al tocar disuelve el sentido que reclama, su más lejana implicancia, ahora conmovedora por lo que niega. Pero habría allí un hacer solo posible en la dificultad, en lo que dificulta el acceso, y el propio poema sería el riesgo tomado por aquello que, sin hablar, ni amordazar lo indecible, se vuelca sobre él a esparcir el sentido inacabado de lo que reprueba negándose, incluso a aparecer en clave de representación de eso que por negarse ya no puede sustraerse, ni restarse.

¿Cuál es el desciframiento menos exacto que podría definir el resto adeudado? En principio, la aparición del sentido en el inacceso de la ruptura. En la visualización de ese problema, el sentido vuelve a aparecer en signo de falta, en ruptura con la desaparición. De esta forma, plantea Nancy, "la poesía afirma entonces el acceso, no en el régimen de la precisión susceptible de más y de menos, de aproximación infinita y de desplazamientos ínfimos-, sino en el de la exactitud. Está hecho, está cumplido, el infinito es actual” (Nancy 2013; 122).

El umbral es el acceso invisible que el poema pareciera reclamar. Violencia de ese afuera invisibilizado ahora por el sentido del acceso (Nancy, 2013; 120). Agonía dispersa en multiplicidad de lo que afuera indaga una deuda, porque allí quizás radique una de sus diferencias 
más agónicas. Lo que vendría a permanecer siempre inaprensible es el indicio de acceso a aquello que las palabras no pueden someter por ilegible y anclado a la opacidad. Dicho de otra forma, acceso al espacio de indagación de la hostilidad, pero ahora en el contexto de la violencia como marca desmedida del poema.

"Poesía comporta siempre una convocatoria más o menos subrepticia a la efusión silenciosa" (Nancy, 2013; 144). Bajo esta premisa es que el poema derrama un desequilibrio para la violencia, ya partida como sentido. La efusión silenciosa no es tanto el poema que desciframos, sino justamente la forma en que se cifra la lectura y la posición del cuerpo sobre y ante ella. Marca irremediable y dispersa de la agonía. Umbral de acceso a lo inaudito, silencioso, o perdido por ahí, bajo la espesa niebla que cubre el campo, allí donde solo se pudo decir lo que no podríamos ya decir (Esposito, 1996; 146). Diríamos que en esa forma de articular el poema aparece una lectura, justamente en ese derrame de silencio habita, cuerpo y materialidad de la deuda, como exceso de vestigio:

"La poesía es entonces la negatividad donde el acceso se vuelve lo que es: aquello que debe ceder y, por eso, empezar por eludirse, negarse. El acceso es difícil, eso no es una cualidad accidental, quiere decir que la dificultad hace el acceso. Lo difícil es lo que no se deja hacer, y es propiamente lo que hace la poesía" (Nancy 2013: 121).

Acceso de lo inaudito como seña o rastro. Lugar de negación como práctica de dificultad. Acceso indebido e irreparable. El poema resulta alterar la condición misma de la poeticidad, es decir, en el espesor impolítico del desastre (Esposito, 1996; 146) las palabras conferidas por esa resistencia -también a la infinidad del lenguaje- comportan un tramado de indecibilidad. El poema viene a descentrar el sonido con que la escucha lo pone en obra, en materialidad crítica, en superficie extraña y desconocida.

Lo que accede sería una cierta evasión, aquello que, eludiéndose como falta, deuda, lleva al poema a salir del acceso como dificultad. Bajo esta premisa, lo que indica la dificultad es justamente lo inaccesible, desciframiento político de eso propio que el poema porta cuando 
desoculta, diríamos, esa politicidad reclamada. La dificultad sería, entonces, una posición politizada del poema cuando lo indecible intenta advertir su imposibilidad, de acceso y negatividad, de resto ineludible.

Desde otro punto de vista ahora, y bajo el mismo problema, en su ensayo titulado "Lo excrito", Jean-Luc Nancy plantea una serie de desplazamientos ligados a la escritura y a una cierta relación significativa con el sentido:

"La imposibilidad de comunicar cualquier cosa sin tocar el límite en el que el sentido todo entero se derrama fuera de sí mismo, como una simple mancha de tinta a través de una palabra, a través de la palabra "sentido". A ese derramamiento del sentido que produce el sentido, o a ese derramamiento del sentido a la oscuridad de su fuente de escritura, yo lo llamo lo excrito" (Nancy, 2002; 39).

Lo excrito también sería el momento en que esa palabra volcada en el desastre contrae la indecibilidad de su apropiación. Lo excrito de ese derramamiento, siguiendo a Nancy, vuelve en cifra indecible eso que comienza a derramarse. El poema aparece para que la caducidad haga sombra sobre las palabras y estas, destinadas a establecerse en el olvido de su clausura, extrañen el tiempo de la significación remota sobre la experiencia del desastre, ya sin tiempo, ni apertura escritural.

El poema como algo que falta y que el sentido debe inaugurar. Umbral y acceso. Retiro y acceso de violencia que, estando o no abiertos - en apertura hacia la letra-, debe encontrar una línea de sentido, una forma de desapropiarse del significado de las palabras que ahora ya pierden el sonido que las va llamando. La poesía, siguiendo a Nancy, sería una deuda, que luego de una violenta entrada, debe ahora reencontrarse con el sentido, en una búsqueda sin trazado, bajo condición de dificultad: "De repente ( ceden su sentido, y la dificultad está ahí, sobrecogedora" (Nancy, 2013; 122). Esta gravedad dificulta la posición de búsqueda de ese derramamiento, aquello que en su exceso debe volver a 
su espacio inicial. Espacio en que el desastre inopera y subordina la colisión de este pensar al desciframiento del desierto que la va tramando.

Lo que golpea, sacude, derrama. Asiste a su propia definición en el momento de ejecución del golpe, en la forma como se despliega la materialidad de su entonación: “Cantar también, por consecuencia, timbrar, entonar, sacudir o golpear" (Nancy, 2013; 125). Democracia ejecutada sobre el cuerpo, posición crítica subordinada, resignificación del Estado, biopolítica de la escritura, la mano que rompe lo que no debe asignarle al delirio, a lo que significa por un fragmento de invisibilidad, ajeno al orden, solo temblor o agonía, desastre, entonces ningún fundamento ligado a lo absoluto o exacto podría encontrarse allí, en su desciframiento político no hay protocolos:

"La poesía es la acción integral de la disposición al sentido. Es cada vez que tiene lugar, una exacción de sentido. La exacción es la acción de exigir una cosa debida, incluso la de exigir más de lo que es debido. Lo que es debido mediante la palabra es el sentido" (Nancy, 2013; 124).

La exacción porta una entrada excesiva, una aparición como reapropiación de la violencia que lo origina (Esposito, 1996; 147). Lo que habría que interrogar en este ensayo de Nancy es la exacción como una forma de deuda que la violencia, sin mayor dificultad, pone en obra en el poema. Quizás, lo que habría que señalar allí es que el poema, por un lado, lo que vuelve disposición al sentido es justamente la incapacidad de leer la deuda como una extracción performativa, por otro, como el momento en que esa deuda se deja leer en el retiro de sentido que implica tal exacción.

La dificultad del acceso invade como sentido. El poema exhibe lo inexpresado sin ceder, anclado a la lengua que lo va extraviando, errando (Blanchot, 2019; 15). La lectura del poema guarda estricta relación con la presencia inmediata del desastre, de un «no hacer de la poesía» (Nancy, 2013). Habría en la lengua del poema una conmoción violenta de lo indecible (Esposito, 1996; 147). 
El poema aquí habría tomado forma política de fractura y desplazamiento. Trazo inabordable que canta, golpea. La exacción es un golpe. El impacto certero de una insignificancia que, en los bordes de su sentido, parece indagar en el temblor de esa colisión, de eso entregado siempre en falta, en falla, en rastro de sentido, pero también de residuo que la violencia no para de asignar, un lugar de restos, ruinas de habla, donde nadie dice.

La poesía siempre debe disputar ese resto adeudado, pues esa fracción comporta una apertura extraña de sentido. El exceso que allí tiembla no es un lugar al que llegar, ni algo posible de reconocer, es siempre la agonía de la oscuridad que vuelve de lo escindido, llena de cicatrices (Cixous, 2006; 60), palabras que ahora simulan el temblor de lo que fue posible a través del poema. Resto inexpresado de un rastro que el cuerpo no puede devolver ilimitado y silencioso (Esposito, 1996; 138), poema de su propio desastre acústico. Lo inaudito del estruendo es lo inaccesible de la violencia.

Ahora bien, si seguimos con atención la crítica de Jean-Luc Nancy, quizás debiésemos advertir que la relación entre hacer y deuda en el poema guarda un espacio común: existir el sentido, hacer existir el sentido, donarlo como existencia. Y ese sentido siempre guarda relación con algo que la palabra debe. Pero el sentido no sería siempre una deuda que las palabras contraen. Por el contrario, su propia contracción entendería a la deuda como espacio de donación ilimitada, indefinida, improbable.

Esa productividad y lejanía proviene de la circulación de deuda. Hay una deuda que el poema reclama y no correspondería al acceso de sentido, ni a la forma en que ese acceso se configura. Allí donde palabras, ilimitadas en su dominación, vuelven a poner en escena un supuesto sentido inacabado. De lo que podemos desprender de la compleja relación entre acceso y sentido se abre la dificultad. La dificultad de acceso, por un lado, el momento en que lo inacabado del sentido se transforma en una escena de lectura configurada por la violencia, por otro.

El poema, buscando su lengua política, relaciona siempre su capacidad formal con su riesgo discursivo. No solo en relación con el poder que lo trama, que configura el espacio donde este pretende diseñar una lectura -vincularse con cierto estado de lengua-, sino también con los procedimientos materiales que culminan con ese hacer sentido del poema. De esta forma, el 
poema siempre puede ser la imagen ausente en el momento de su desaparición (Blanchot, 2019; 31). Quizás su acceso al sentido es el lugar donde la circulación es interrumpida por la opacidad, pero al mismo tiempo, la opaca imagen de esa desaparición es la que permite descifrar, siempre de forma preliminar, los contenidos que diagrama la violencia.

El poema como opacidad. La opacidad como poema. La tecnificación del relato, o la instrumentalización de esta narrativa política, exige un modo de hacer que las palabras refuerzan todavía en esa exacción. En la exacción no hay poema. Lo que estaría ahora en deuda sería justamente la fractura de este. Sin embargo, bajo la lógica del desastre, las palabras comienzan un vaciamiento radical porque la propia desaparición del sentido, relacionada a su configuración político-histórica, esa que justamente tiene como tarea incansable la expropiación y exterminación del sentido (Nancy, 2002; 18), vuelve a edificar una política de su propia cancelación:

"Nuestra historia ha sido representada como el proceso de un derrumbamiento o de una destrucción del sentido, en el salvajismo planificado de una civilización venida a su límite, ella misma vuelta la civilización de la liquidación del sentido de toda "civilización", y del sentido en general" (Nancy 2002: 17).

Lo que se debe estuvo ahí, en algún lugar fue definida su forma, sus principales relaciones, los circuitos a los cuales pertenece, el tránsito de su circulación, la violencia con que entra ya configurada. El poema es una definición que no llega. Que no tiene llegada, pero que, sin embargo, a raíz de un vínculo específico con la narrativa de época -para situar al contexto de democracias radicalizadas en la subordinación- debe siempre poner en falta, en ausencia, el vacío que lo sostiene. Exacción sería la forma que la configuración técnica del poema debe autorizar, pero hay falta, ausencia, resto inexpresado (Esposito, 1996; 138).

Hacer, fabricación, utensilio, allí puesto, como una luz incesante, en la reapertura del problema. Hacer y fabricar. Fábrica de quienes fabrican. Oportunidad de desacato y escritura, aquello que, en el hacer, en el poner otra vez el cuerpo donde ya no está, donde lo que tuvo alguna vez de mecánico fue arrebatado por su anverso, pueda aparecer aquello que falta, el 
sentido de lo que no debe comparecer. Es en ese lugar donde el poema no lee lo irreparable, que ya no puede ser la crisis de sentido, pues ya no sabe cómo desplegarse en su interior. Crisis y poesía se entrelazan, vuelven de su lectura e interrogan ese poema inaudito (Esposito, 1996; 148), imposible por silencioso y oscuro de ser descifrado como acceso o exacción.

\section{II.}

"El lenguaje no solo no es nada ajeno a la violencia, sino que constituye el canal privilegiado precisamente cuando la violencia renuncia a presentarse como tal para asumir una forma superior de dominio" Roberto Esposito.

El sentido como vínculo determinante con la violencia. Indicio - de acceso y dificultadque infringe las condiciones en que el poema se escribe, roza, indaga, y pone al tanto de lo que no vemos como expresado, articulado, en reverso de su dificultad: el sentido de la violencia guarda un poema inaccesible por encriptado sobre el vínculo de cuerpo y poder. Su forma de pensar la relación tendría que ver con el carácter del poema. En su ensayo "Un pensamiento finito", Nancy plantea lo siguiente:

"Pensamiento simple, y duro, y difícil. Pensamiento rebelde a todo pensamiento, y que el pensamiento, sin embargo, conoce -comprende y sientecomo eso mismo que piensa en él. Pensamiento en insurrección permanente contra toda posibilidad de discurso, de juicio, de significación, y también de intuición, de evocación o de encantamiento. Pero pensamiento que no está presente sino para esos discursos o para esas palabras a las cuales hace la violencia -de las que él es la violencia-. Es por ello que este pensamiento se llama también "escritura", es decir, inscripción de esta violencia, y del hecho de 
que para él todo sentido es excrito, no se vuelve sin resto, y que todo pensamiento es un pensamiento finito de este exceso infinito" (Nancy, 2002: 8).

Lo que la violencia determina sobre el sentido es la agonía de la relación cuerpo-poema, y de la ficción que lo descubre afirmando la posibilidad de resistir a cierta infinidad que la lengua impone como ficción de sentido. El acceso como umbral de entrada. La dificultad como posibilidad de asignarle su violencia. Violencia de entrada. Violencia en acceso. Lo que dificulta el acceso es que no requiere de una figuración técnica, ni de un giro trascendental, para estar allí, a causa de un espacio salido del desastre, como poema, presentado ahora como rechazo del umbral, porque lo que este desordena es el fundamento mismo del acceso.

Quizás debiésemos poner en cuestión el carácter finalmente crítico de la comprensión que de la poesía tiene Nancy. Más allá del entramado escritural conjeturado alrededor del problema, todavía se piensa como el instante técnico de despliegue de una forma superior de exactitud y verdad, al mismo tiempo de condiciones de acceso y hacer del sentido. Por otro lado, la violencia examina y garantiza la circulación de un habla restringida y en carencia, como espacio diferenciador, de aquello que por oscuro no puede ver las zonas de oscuridad de las cuales proviene, y de esa máxima circulatoria, que contempla la noción de poema como la puesta en obra de un silencio conmovedor, de un registro sobrecogedor de lo que hemos puesto en práctica -como liberación del sentido estrechado por el exterminio y la actualización de la técnicización-, y quizás esto no sea más que el despliegue político de la violencia que arremete como silencio.

La puesta en escena de una técnica de representación de la lectura y la ampliación de la productividad, a su vez, bajo el régimen de las palabras como dispositivos de poder, podría pensarse como ensayo violento. Lo que altera esta regresión de las palabras trazadas como violencia, con aquella deuda violenta que restituye el sentido sería el poema, consagrado ahora a la lectura de una forma de vigilancia y desastre. Ese hiato ocurrido a partir de pensar lo político de esta relación, pone en escena la restitución de un significado ya leído por la violencia del régimen en la exaltación del olvido (Blanchot, 2019; 10). 
Poema y violencia parece estar delineado por la complejidad del desastre (Blanchot, 2008; 376), allí donde la palabra que viene de la desaparición sustituye su propio conflicto con la imagen que excede -que es desgarramiento, resto, pérdida-. En ese detalle excesivo -narrativa de excesos-, la agonía del poema vuelve a simular una resistencia dócil, cuyo desplegar subrepticio se inserta indecible (Foucault, 2002: 11), pero ahora como cuerpo de su propia diferencia. La falta de desciframiento en ese "hacer" insurrecto, en principio, nos conduce a la idea de que el poema no debe ni adeuda con el sentido ninguna relación particular o predilecta, sino más bien la posibilidad cierta de su pronta y radical interrupción a partir de una violencia siempre operativa. Al mismo tiempo -y leyéndolo de un modo crítico- el poema se insurrecta cuando la imagen trae la interrupción del sentido descifrado en el acceso, pues allí estaría su resistencia (Nancy, 2013; 146).

En el poema no hay una imagen que adeude, sino más bien la propia falta de escritura es lo que debe a su imagen faltante. Esta materialidad del poema, que acusa una entrada al régimen de violencia en forma de economía visual, debe a su condición de lectura también una imagen que desaparece al mismo tiempo que del poema se retira el cuerpo productivo. En esa imagen hay una resistencia. Lo que resiste es el develamiento de que la escena de lectura es el presente inviable del tránsito de la violencia. Se escribe bajo reglas y vigilancia del desastre.

El poema piensa su política de opacidad cada vez que resignifica la cancelación de lo irreparable. Si la organización simbólica del capital también requiere de un lenguaje experto que pueda calificar la falta, lo que el poema viene ahora a interrumpir de este desciframiento es justamente la posibilidad de articular una lengua hostil que no devenga necesariamente palabra errante -aunque siempre en confrontación- sino más bien la posibilidad de un poema aberrante, retirado contra el espacio del cual desea venir (Blanchot, 2019; 61).

\section{III.}

Desastre y poema parecen comportar un espacio poético de pensamiento, líneas ocultas que van tramando la posibilidad de extraviar-se, allí donde las palabras significan su caducidad, como descampado inmemorial de un vacío desplegado interior, allí en desastre continuo, como aquello que no estando allí vuelve a poner en relación el sometimiento experiencial del poema, 
pero ya no solo el poema, agonía de lectura que debe, una línea de sentido no sometido al tramado irreparable de su opacidad, sino aquel opaco indicio que se pierde como resto, ahora contrarrestado por eso de inmemorial que contiene.

¿Dónde habría de estar ese vaciamiento, deuda irreparable, que la violencia trae al desastre? Por el momento en una extraviada opacidad del vacío, elemento discursivo que no retira la presencia de lo que se apresta a su búsqueda, a la particular ironía con la que devuelve la representación de la violencia en el poema que el desastre es cuando se oculta y aparece:

"El desastre no hace que el pensamiento desaparezca, sino que lo convierte en cuestiones y problemas, afirmaciones y negaciones, silencio y habla, signo e insignia. Entonces, en la noche sin tinieblas, privado de cielo, lleno de la ausencia del mundo, en retirada de todo presente consigo mismo, el pensamiento vela" (Blanchot, 2019; 51).

Bajo la vigilancia del desastre, las palabras ya vacías, continuidad de escritura radical, desaparecen. Lo que no aparece como ausencia. Silencio parece apartarse, en el vocablo del desastre, a un espacio en expedición, instancia de palabras perdidas que ponen al extravío fuera de toda vigilancia. Allí no hay poema que el acceso al sentido pueda consagrar como parte de su ausencia, horror afirmado como técnica de la significación, vacía ya de todo "morir inmemorial" (Blanchot, 2019; 37), como un ejercicio técnico intentando imaginar lo que allí hay de privación. Bajo esa tensión, el poema se vuelve presencia del desastre en el silencio que lo llama. Lo que no desaparece de lo velado en el pensar: "En el trabajo del duelo el dolor no trabaja: vela" (Blanchot, 2019; 51).

Errancia como un exceso de error que interrumpe. La escritura desaparece de su ausencia. La errancia de las palabras, dadas por colisión en el espacio del desastre, viene a preguntar por esa disolución significante de lo retirado por completo del fragmento, el desastre no tiene antes, ni después, se desfigura a partir de su llegada, bajo los límites de su contratiempo, y nada sabemos acerca de su venir y disolución, desastre después del desastre (Blanchot, 2019; 12), poema antes de llegar a la escritura (Cixous, 2006). 
Está allí lo que se ausenta. Como si el poema pudiese ausentarse cada vez, allí tramado, resto indescifrado, donde ningún acceso sería posible de atender ante la ausencia, o ante la desaparición. Lo indescifrado, el resto que en su interior vuelve a restarse, sería lo político del poema. Lo que se ausenta ya no es siempre la pérdida, sino el despliegue de ella sobre los cuerpos. A la desaparición le corresponde siempre opacidad. Opacidad subordinada nada más que al ejercicio incansable de quebrar y modificar sus relaciones con su propio resto, su indefensión como práctica de existencia.

Pisagua, Chacabuco, quizás no haya ahí, en esos nombres, la dislocación de sentido que requiere el acceso, como el sentido que resiste, que niega lo inaudito para cazar una sombra, en ese breve silencio, palabra y dolor volviéndose una extrañeza para el lenguaje de la muerte que ya tiene una escena técnica narrada, ahora material, circulante, pero extrañeza de sitio, como la oscuridad que deja la sombra para trazar la lengua que cae sobre ella, dislocada, revuelta, donde el acceso del poema no tiene lugar, sino espacio de despliegue sobre el cuerpo. Pisagua, Chacabuco, acceso a la actualidad del desastre, a lo que no piensa otra cosa que el trazado de ese poema en resistencia que aterra a su propia diferencia, la que de vez en cuando vuelve a pensar el sentido de eso violento adeudado, debido, y como cualquier otra posibilidad volcándose infinita.

\section{Bibliografía}

Blanchot, Maurice (2019). La escritura del desastre. Madrid. Editorial Trotta.

Blanchot, Maurice (2008). La conversación infinita. Madrid. Arena Libros.

Cixous, Hélène (2006). La llegada a la escritura. Buenos Aires. Amorrortu.

Esposito, Roberto (1996). Confines de lo político. Madrid. Editorial Trotta.

Foucault, Michel (2002). El orden del discurso. Barcelona. Tusquets. 
Nancy, Jean-Luc (2013). La partición de las artes. Valencia. Pre-textos.

Nancy, Jean-Luc (2002). Un pensamiento finito. Barcelona. Anthropos. 